\title{
Rupturas, neogolpismo e América Latina: uma análise sobre Honduras, Paraguai e Brasil
}

\author{
Matheus Alexandre Araújo \\ Universidade Federal do Ceará, Centro de Humanidades, \\ Departamento de Ciências Sociais, Fortaleza, CE, Brasil (UFC)
}

\author{
Vanessa dos Santos Pereira \\ Universidade Federal do Ceará, Centro de Humanidades, \\ Departamento de Ciências Sociais, Fortaleza, CE, Brasil (UFC)
}

\begin{abstract}
Rupturas, neogolpismo e América Latina: uma análise sobre Honduras, Paraguai e Brasil
Resumo: Ainda que previsto o esgotamento do ciclo de governos de esquerda latino-americanos, a onda rosa, o que aconteceu nos últimos períodos tem surpreendido. Não se esperava quebra nas regras do jogo, como em Honduras (2009), Paraguai (2012) e Brasil (2016), países que interpretações errôneas das instituições resultaram em impedimento dos mandatos presidenciais. Assim, este trabalho tem por objetivo compreender, a partir de uma perspectiva comparada, esses três processos. Para tanto, classificaremos os processos de deposições ocorridos nos três países como neogolpismo para diferenciar dos padrões anteriores, pois não contam com participação direta dos militares e seu processamento acontece por meio das instituições vigentes. Dissertaremos, ainda, sobre como esses eventos reverberam na qualidade democrática em América Latina e os limites das análises que enfatizavam a consolidação da democracia nos países estudados.
\end{abstract}

Palavras-chave: Neogolpismo. Democracia. América Latina.

\section{Ruptures, neo-coups d'état and Latin America: an analysis of Honduras, Paraguay and Brazil}

Abstract: Although the conclusion of the cycle of leftist governments in Latin America was foreseen, the recent pink wave has been a surprise. Disruptions in the rules of the game were not expected, such as those that occurred in Honduras (2009), Paraguay (2012) and Brazil (2016), countries where erroneous interpretations by institutions toppled presidential mandates. The objective of this study is to understand these three processes, using a comparative perspective. We classify the depositions that took place in these three countries as neo-coups d'état to distinguish them from previous ones, because they did not include the direct participation of the military and they were processed through the ruling institutions. We thus reflect on how these events reverberate in the quality of democracy in Latin America and the limits of the analyses that emphasize the consolidation of democracy in the countries studied. Keywords: Neo-coups d'état. Democracy. Latin America.

Recebido em 21.05.2017. Aprovado em 05.09.2017. Revisado em 16.11.2017.

C O(s) Autor(es). 2018 Acesso Aberto Esta obra está licenciada sob os termos da Licença Creative Commons Atribuição-NãoComercial 4.0 Internacional (https://creativecommons.org/licenses/bync/4.0/deed.pt_BR), que permite copiar, distribuir e reproduzir em qualquer meio, bem como adaptar, transformar e criar a partir deste material, desde que para fins não comerciais, e que você forneça o devido crédito aos autores e a fonte, insira um link para a Licença Creative Commons e indique se mudanças foram feitas. 


\section{Introdução}

Entre as décadas de 1970 e 1980, inicia-se o processo de globalização neoliberal. Esse impulso ocorre, primeiramente, em razão do colapso do modelo de bem-estar social. O golpe militar, no Chile, ofereceu, então, uma solução para essa crise. A partir dessa primeira experiência, concluiu-se que o neoliberalismo era um projeto necessário para a "restauração do poder de classe" das elites econômicas, outrora limitado pelas regulações estatais (HARVEY, 2008, p. 16). Um segundo fator que colaborou para a subsequente hegemonia neoliberal foi o fim da União Soviética, tornando o mundo unipolar (SADER, 2008, p. 5). Esse último configurou-se como um elemento fundamental para a derrota ideológica das esquerdas no mundo, fazendo surgir a crença de que não há alternativa.

A intervenção do Estado nos mercados, agora, deveria ser mantida em um nível mínimo, livrando o capital de travas que impediam sua circulação: tratava-se de promover a precarização das relações de trabalho, a desregulação e financeirização da economia. A condição para que, posteriormente, o neoliberalismo se estabelecesse nos países latino-americanos, segundo Emir Sader (2008), foram as ditaduras militares que impuseram forte repressão às esquerdas e aos setores organizados das classes trabalhadoras em ascensão em boa parte dos países. Foi na América Latina “onde nasceu o neoliberalismo e o lugar onde mais se expandiu” (SADER, 2008, p. 13), sobretudo nas décadas de 1980 e 1990, com uma série de reformas institucionais que retiram do Estado sua capacidade reguladora, transferindo funções para o mercado e privatização de empresas públicas.

Na primeira década do século XXI, no entanto, a América Latina foi marcada por um fenômeno improvável. Testemunhamos um processo que foi na contramão do que ocorria no mundo àquele momento. A eleição de partidos, movimentos e lideranças de esquerda, para cargos majoritários na maioria dos seus países, em um contexto de crise global das ideias de esquerda, com o fim do socialismo real, hegemonia do neoliberalismo, sobretudo nos países capitalistas centrais, e sensação de fim da história. Era o giro à esquerda latinoamericano. O episódio inédito no subcontinente marcado por regimes oligárquicos, ditaduras civis-militares e mesmo a eleição democrática de governos conservadores, ficou conhecido como onda rosa (PEREIRA, 2011, 2015). Tais governos eram caracterizados, dentre todas as suas especificidades, pela crítica ao modelo econômico neoliberal e a redefinição do papel do Estado, levando analistas a falarem da inauguração de um período pós-neoliberal no subcontinente (ver p. ex. SADER, 2009).

Com o fim do consenso das commodities, a emergência de crises econômicas, o esgotamento da política neodesenvolvimentista e a limitação de projetos de distribuição de renda desses governos, tornavamse perceptíveis as dificuldades que apontavam para o encerramento dessa era. Porém, ainda que previsto o esgotamento desse ciclo, o que se sucedeu nos últimos períodos tem surpreendido, sobretudo, a ala politóloga que possui veemente crença institucionalista na democracia e no equilíbrio de poderes. Não se esperava quebra nas regras do jogo, como em Honduras, Paraguai e Brasil, países que interpretações errôneas das instituições resultaram em impedimento dos mandatos presidenciais.

Compreendemos que as deposições de Manuel Zelaya, Fernando Lugo e Dilma Rousseff são, também, lutas simbólicas. Na decorrência destes processos, há uma disputa feita por grupos opostos pela narrativa do evento. Os que tratam o processo como golpe e os que negam. Assumimos, aqui, o lado daqueles que definem o processo como golpe. Devemos, no entanto, ir além do mero emprego político do termo e perguntarmo-nos até que ponto seu uso é adequado.

Segundo Bianchi (2016), a expressão golpe de Estado, a partir século XX, passa a ser entendida como o próprio ato de conquista do poder político, podendo envolver atores que estavam fora do palácio. No entanto, essa literatura considerou como eventos golpistas as operações predominantemente militares. Para Bianchi (2016, p. 3), é preciso repensar o conceito, pois uma "definição tão limitada não permite considerar a hipótese de golpes promovidos por grupos do poder Legislativo ou Judiciário ou por uma combinação de vários grupos e facções". Para Renato Perissinoto (2016, p. 2), um golpe, portanto, "é, essencialmente, a substituição de um governo por meio de procedimentos não previstos; um golpe de Estado é basicamente o rompimento das regras do jogo sucessório."

Entretanto, operamos com a palavra neogolpismo a fim de destacar que tais atos são rupturas distintas das observadas nos países latino-americanos entre os anos 1960-1980, que contavam com a participação direta dos militares. Os novos tipos de golpe possuem feição de legalidade e buscam, preferencialmente, seu processamento dentro das instituições, "flexibilizando critérios do processo de impeachment, o qual é constitucional, para que governantes sem crime de responsabilidade pudessem ser retirados, o que é inconstitucional" (REIS, 2017, p. 4). Segundo Juan Gabriel Tokatlian (2009, p. 1),

el 'nuevo golpismo' está encabezado más abiertamente por civiles y cuenta con el apoyo tácito (pasivo) o la complicidad explícita (activa) de las Fuerzas Armadas, pretende violar la constitución del Estado con una 
violencia menos ostensible, intenta preservar una semblanza institucional mínima (por ejemplo, con el Congreso en funcionamiento y/o la Corte Suprema temporalmente intacta), no siempre involucra a una gran potencia (por ejemplo, Estados Unidos) y aspira más a resolver un impasse social o político potencialmente ruinoso que a fundar un orden novedoso.

Os novos golpes são mais sutis no uso concentrado da força, como nota Fabricio Pereira (2017). A aparência institucional facilita o reconhecimento dos novos governos por parte da comunidade internacional. $\mathrm{O}$ uso de força militar não é um componente necessário para essa definição, embora possa ser utilizado. No entanto, mesmo que a participação de forças militares ocorra, a aparência institucional é minimamente preservada.

Por fim, este trabalho tem por objetivo compreender, a partir de uma perspectiva comparada, esses três processos, evidenciando o papel de grandes empreendimentos de comunicação, do Poder Judiciário, a participação do empresariado e os impasses institucionais que acarretaram a deposição. Esta escolha metodológica permite ampliar nosso olhar como pesquisadores, chamando a atenção para ocorrências que poderiam ser naturalizadas em um estudo de caso nacional. Permite-nos, ainda, observarmos movimentações comuns e diferentes, encontrar explicações para além das causas internas, bem como fornecer novas pistas para a investigação.

\section{Estado democrático de direito: a fantasia latino-americana}

Democracia é um conceito em disputa. Para a esquerda do espectro político, trata-se de um regime que conceda maior autoridade e participação efetiva às pessoas comuns, de forma que o ideal normativo de igualdade política seja plenamente realizado, observando que não há democracia efetiva se as hierarquias presentes no ambiente de trabalho ou espaço doméstico não são questionadas (ver p. ex. PATEMAN, 1992). Para o pensamento conservador, no entanto, a democracia não passaria de um processo de legitimação de uma autoridade política por meio do voto popular.

Joseph Schumpeter (1961), um dos principais precursores das teorias elitistas da democracia, afirmava que tudo tratava-se apenas de um ritual para garantir o consentimento dos governados, já que a igualdade seria ilusão. Influenciado por estas ideias, Anthony Downs (1999) acreditava na necessidade da obtenção da maioria popular, pois ela garantiria que os eleitos fossem fiéis cumpridores da vontade do povo. Para Robert Dahl (2005), autor liberal também influenciado pelas concepções schumpeterianas, o voto é um dos requisitos básicos de uma democracia eleitoral. Ele apresenta o princípio da intercambialidade, no qual nenhum grupo ou indivíduo tem poder de veto sobre a maioria gerada no processo do sufrágio.

Mesmo nas compreensões minimalistas de democracia, exige-se isso: o consentimento popular por meio do voto. É possível não esgotar as possibilidades de democracia neste procedimento e reivindicar mais. No entanto, o voto popular está sempre lá como consenso de que é a única forma legítima de alcançar o poder.

Seguindo essa concepção limitada, ainda assim, a ausência de democracia seria um fenômeno marcante na história da América Latina. A história do subcontinente é marcada por regimes oligárquicos e ditaduras civis-militares. A democracia, aqui, constituiu-se como uma exceção. Na região, o único governo eleito de forma democrática, a partir das esquerdas, havia sido o de Salvador Allende, no Chile (1970), destituído, em seguida, por um golpe. Como afirma Fabricio Pereira (2015, p. 17), "tinha-se dificuldade das frágeis democracias da região - quando elas existiram ou ensaiaram existir - em se ampliarem incluindo as esquerdas".

Após a redemocratização iniciada na década de 1980, os países latino-americanos vivenciaram seu maior período democrático. No entanto, no mesmo período, a cartilha neoliberal foi fortemente aplicada. Em Honduras, o fim do regime militar ocorreu em 1980. Os governos que ulteriores realizaram o desmonte da reforma agrária e o abandono de funções de proteção social em áreas como habitação, trabalho e seguridade social (ROMERO, 2014).

No Brasil, a abertura política iniciou-se em 1985. Anos depois, o presidente Fernando Henrique Cardoso (1995-2002) fez do seu governo o principal momento de implantação das políticas neoliberais, com privatizações de empresas estatais e aumento dos índices de pobreza, miséria e desemprego (LÓPES SEGRERA, 2016). Em Paraguai, o retorno da democracia acontece em 1989, após 35 anos consecutivos de período ditatorial. Os governos posteriores do partido colorado não hesitaram em colocar nas mãos do capital estrangeiro os processos de extração dos poucos recursos naturais, além da produção e distribuição dos alimentos, promovendo, ainda, privatizações de setores chaves da economia. A curta e difícil "era das democracias na América" (REIS, 2017, p. 1) foi encerrada, no entanto, em 2009, com mais um golpe de estado, em Honduras, que violou o instrumento basilar do regime democrático: a soberania popular por meio do voto. Em 2012, isso repete-se no Paraguai e, em 2016, no Brasil. 


\section{Honduras}

A derrubada de Manuel Zelaya do governo de Honduras, em 2009, inaugurou o neogolpismo na América Latina. Anterior ao evento, Honduras contava com dois partidos que hegemonizavam a política local. Seu sistema era considerado bipartidário. Além dos dois principais partidos, o Partido Nacional (PNH) e o Partido Liberal (PLH), do qual o presidente deposto fazia parte, havia, ainda, três pequenos partidos de esquerda e centroesquerda. Honduras era, e ainda é, o país centro-americano com menor renovação das elites políticas e maior intervenção do empresariado no poder público, fortalecida pelas privatizações neoliberais (AGUILAR, 2013).

No início do século XX, empresas bananeiras de capital norte-americano estabeleceram-se no país com todo amparo do Estado, que as ofereceu concessões de terras, águas, isenções de impostos e outros benefícios econômicos. Estas, por sua vez, manipulavam partidos autoritários e seus caudilhos, financiando suas ações armadas em disputas com outras facções para, dessa forma, governos que ampliassem seus benefícios fossem constituídos (ROMERO, 2014, p. 10). As empresas bananeiras formaram-se como peças fundamentais do jogo político hondurenho, capazes de decidir os rumos do país, mantendo intacto o exercício autoritário da política.

A partir de entonces, el alineamiento incondicional con los Estados Unidos ha sido un componente decisivo de la política autoritaria hondureña. El principio de lealtad ideológica del autoritarismo, desde entonces hasta la actualidad, ha cobrado forma en la proclama y práctica del anticomunismo hondureño. Aún hoy, 25 años después de extinguida la Unión Soviética y finalizada la guerra fría, cuando los escenarios globales son muy diferentes, los autoritarios de Honduras siguen lanza en ristre contra aquel molino de viento, como se evidenció en el golpe de Estado de 2009. (ROMERO, 2014, p. 21).

Segundo Ramón Romero (2014, p. 11), em Honduras têm prevalecido uma indisposição de reconhecer os espaços da oposição e o golpe de Estado de 2009, após 29 anos de transição democrática, confirmou que as elites econômicas do país mantêm atitudes autoritárias, porém com convenientes roupagens democráticas.

Alguns analistas, poucos meses antes da deposição do presidente, afirmavam que a democracia hondurenha caminhava para sua consolidação (TAYLOR-ROBINSON, 2009). Afirmação questionável e que não se comprovou, colocando em cheque a crença de que as democracias não são passíveis de retrocessos quando interesses hegemônicos são contrariados.

Mesmo com o resultado eleitoral tendo sido questionado pela oposição que, por sua vez, exigiu a revisão das atas eleitorais, Manuel Zelaya assume e depara-se com dificuldades econômicas, devido à recessão estadunidense, em 2008. Para tal desafio, o governo de $\mathrm{Mel}$ aplicou estratégias tanto tradicionais como novas. Além de empréstimo no Banco Mundial, o presidente recorreu a Hugo Chávez para obter petróleo e ajuda em temas de desenvolvimento, associando-se, então, a união Petrocaribe, em julho de 2008, para receber petróleo venezuelano por baixo custo e enfrentar o monopólio energético detido pelas transnacionais estadunidenses e europeias. Tal atitude foi fonte de conflitos domésticos. Zelaya foi acusado de levar Honduras para uma política de esquerda, não aprovada pela maioria da população. O líder do partido liberal não foi eleito com plataforma progressista, tendo realizado o inesperado policy switch após assumir (CUNHA FILHO; COELHO; PÉREZ FLORES, 2013).

Controvérsia maior foi a iniciativa do Executivo hondurenho de unir-se à Alianza Bolivariana para los Pueblos de Nuestra América (ALBA), liderada por Venezuela, com o objetivo de conseguir fundos para programas de desenvolvimento. Inúmeros grupos manifestaram-se, imediatamente, contrários a decisão: o Partido Nacional (PNH), setores do partido do próprio Manuel Zelaya, o Partido Liberal (PLH) e, sobretudo, grupos empresariais que o qualificaram como "inimigo do setor privado" (MANUEL..., 2015). Somente o Partido Unificación Democrática (PUD), pequeno partido de esquerda, colocou-se abertamente a favor da proposta. A partir daí, Zelaya passou a contar com uma forte oposição parlamentar, inclusive dentro de seu próprio partido, ocorrência inédita na política nacional (TAYLOR-ROBINSON, 2009).

O giro à esquerda tencionou o clima político. Os meios de comunicação hegemônicos passaram a mencionar incessantemente suposta influência de Chávez na política interna e as intenções de Zelaya de perpetuasse no poder. Devido aos votos liberais, que aprovaram a união de Honduras à ALBA, Roberto Micheletti, líder de facção conservadora dentro do partido e com forte influência sobre a bancada no Congresso, obteve apoio de $\mathrm{Mel}$ nas prévias do PLH contra seu vice-presidente, Elvin Santos, que renunciou parar disputar. Santos resultou como vencedor e, desde então, Micheletti perdeu qualquer incentivo de continuar apoiando o governo e sua política de esquerda. O parlamentar passou a utilizar seus amplos poderes e controle sobre a bancada liberal para obstruir a agenda governamental.

A crise hondurenha chegou a seu ponto culminante com o impasse da reforma constitucional e a quarta urna. Na ocasião, o presidente havia decidido convocar um referendo consultivo e não-vinculante, porém sem 
previsão constitucional, para verificar o apoio da população à sua intenção de convocar uma Assembleia Constituinte. A quarta urna seria colocada ao lado das três votações para congressistas, prefeitos e presidente, marcadas para novembro de 2009. Setores do Partido Liberal, liderados por Micheletti, e o Partido Nacional, acusaram Zelaya de bolivarianismo, planejar perpetuasse no poder e atentar contra a ordem democrática. O Congresso usou de inúmeras possibilidades para barrar o referendo, bem como o Poder Judiciário agiu para impedir a proposta. Meses depois, o parlamento, de maneira preventiva, aprova uma lei que pró́be referendos 180 dias antes ou depois das eleições regularmente programadas.

Em 25 de junho, os deputados abriram uma investigação sobre a conduta presidencial, apontando o início de um processo de destituição. No entanto, a previsão constitucional que estipulava a possibilidade de um juicio político havia sido extinguida em 2002, durante o governo nacionalista de Maduro. A Constituição previa somente que a Corte Suprema intermediaria conflitos institucionais entre o Congresso e a Presidência. O processo de impedimento não se desenrolaria dentro da legalidade, portanto. No entanto, não foi preciso continuidade desse processo à margem da lei. As Forças Armadas, por solicitação da Corte Suprema, sacaram o presidente Manuel Zelaya, na madrugada de 28 de junho de 2009, de sua casa, ainda de pijama, e o enviaram para exílio na Costa Rica, sem qualquer direito de defesa (REIS, 2017). No mesmo dia, o parlamento aprovou com 122 votos, de um total de 128 membros, uma renúncia que Zelaya sempre negou e nomeou Roberto Micheletti como presidente do Congresso, posteriormente sucessor do presidente eleito até 2010. Os votos corresponderam tanto ao opositor Partido Nacional, como a totalidade do Partido Liberal no governo (LLANOS; MARSTEINTREDET, 2010). Em um bárbaro paradoxo, golpeou-se a democracia, justificando sua defesa.

O golpe recebeu unânime condenação da comunidade internacional. Por meio de seus organismos, negaram-se a reconhecer o novo governo de Roberto Micheletti, suspendendo créditos e programas de ajuda financeira (LLANOS; MARSTEINTREDET, 2010). O governo brasileiro teve fundamental importância no repúdio ao golpismo em Honduras. A posição de Brasília era de que a solução para a crise teria de passar por um acordo que restituísse o presidente Manuel Zelaya para concluir o seu governo de forma pacífica. Não aconteceu. A embaixada do Brasil, então, acolheu Mel durante quatro meses, na capital Tegucigalpa. Comportando-se com morosidade, à princípio, o governo norte-americano, frente as iniciativas do governo de Lula, viuse forçado a agir, enviando Thomas Shannon, subsecretário de Estado para a América Latina, para negociar um acordo que incluía a volta de Zelaya a presidência (AGUILAR, 2013).

Como bem afirmou Aleksander Aguilar (2013, p. 11), "o golpe foi uma resposta da obscura elite hondurenha às medidas que Zelaya implementava, orientadas à justiça social e contra a corrupção e o privilégio estatal [...]". O jogo ainda não acabou. Há denúncias de fraudes e manipulação das eleições de 2013. Profissionais de comunicação que se colocaram contrários ao golpe têm sofrido intensa perseguição governamental. Mais de 30 jornalistas foram assassinados, desde o evento (AGUILAR, 2013). Em 2014, parlamentares do partido LIBRE, composição de líderes egressos do Partido Liberal, movimentos sociais e centrais sindicais, foram expulsos à força do parlamento, com bombas de gás lacrimogêneo, por protestarem pacificamente pelo direito de palavra que estava sendo negado ao grupo político (MANUEL..., 2015). As sequelas do golpe permanecem.

\section{Paraguai}

Fernando Lugo, em 2008, vence o pleito presidencial quebrando a hegemonia de 61 anos do Partido Colorado, oficialmente denominado por Asociación Nacional Republicana. Candidato pela Aliança Patriótica por el Cambio (APC) e com um programa político considerado de centro-esquerda, conquistou a confiança do povo paraguaio através da ênfase dada a pautas negligenciadas pelos governos anteriores. "Havia uma conta pendente de toda a democracia construída, até o momento, desde a questão da terra, passando pela distribuição das riquezas nacionais e a demanda por justiça social" (GÓMEZ, 2012, p. 59, tradução nossa).

Porém, essa transformação não se manifestou, da mesma forma, no arranjo do Congresso Nacional que se manteve majoritariamente composto por partidos de direita: Partido Colorado, União Nacional dos Cidadãos Eticos (UNACE) e Partido Liberal Radical Autêntico (PLRA). Apesar de o vice-presidente, Federico Franco, ser uma liderança liberal, o governo luguista sofreu imensa crise decorrente da ingovernabilidade causada por tais partidos.

Mesmo com todas as limitações, o ex-bispo buscou conduzir seu mandato em consonância com o programa de governo vitorioso nas urnas, em detrimento dos interesses das elites econômicas, que se concentravam em sua maioria no agronegócio, além de buscar combater o narcotráfico. Esses eram os dois principais setores que financiavam os partidos oposicionistas.

Para o sociólogo Tomás Palau Viladesau (2005, p. 36), existem quatro estruturas de poder, no Paraguai, que são: cluster do capital transnacional, os latifundiários, os narcotraficantes e, por fim, os pseudo-empresários. Estes últimos utilizam o Estado e o governo como meio de enriquecimento. 
Las licitaciones amañadas de obras públicas, el contrabando, otras formas de evasiones, el desvío de fondos públicos. Los intermediarios de productos agrícolas se ubican en su mayoría em este grupo. (PALAU VILADESAU, 2005 p. 2).

Muitos desses setores conquistaram e expandiram seus poderes durante a ditadura stronista (19541989) e mantiveram-se intocáveis após a redemocratização. Dentre os grupos beneficiados, os latifundiários e as empresas do agronegócio alcançaram seu auge. A concentração latifundiária ocorreu vertiginosamente durante o regime autoritário. Segundo o relatório da organização internacional Oxfam, 2,6\% de proprietários possuem $85,5 \%$ das terras produtivas do país, hoje (PARAGUAY..., 2017).

Outro setor crucial e de grande interferência política é o oligopólio midiático controlado por sete grupos empresariais que atuam em negócios relacionados com a estrutura produtiva do país ${ }^{1}$. Um dos mais imponentes é o Grupo ABC Color: comandado pela família Zuccolillo e criado durante o período ditatorial, possui laços estreitos com Asociación Rural del Paraguay (ARP) e a Unión de Gremios de la Producción (UGP) que representam, respectivamente, os grandes produtores de soja e os agropecuaristas do país.

Em 2011, o presidente buscou investir em meios de comunicação estatal para poder competir com a oligarquia midiática. Segundo Eugenio Lahera, o monopólio da informação é instrumento necessário no controle do "espacio fundamental de la política, aquel en el que se forman las opiniones y las decisiones de los ciudadanos" (LAHERA, 2004, p. 19). Lugo impôs, ainda, regras de atuação em território paraguaio às empresas Monsanto S.A, Cargill e Río Tinto-Alcan e Bollgard BT.

Apesar do crescimento econômico contínuo, desde 2007, o presidente eleito não conseguiu que a riqueza fosse distribuída significativamente para as classes populares e encontrou sérios entraves para efetuar a reforma agrária. Conseguiu, na medida do possível, implementar políticas de distribuição de renda, além de alargar o acesso à Educação e Saúde. Lugo contou com significativo percentual de aprovação popular durante todo o mandato exercido, porém "a grande popularidade de Lugo não se traduziu em uma posição sustentável no Parlamento. Bastou que fechassem as urnas para que dessem início a um impedimento” (ESCOBAR, 2012, p. 90, tradução nossa). Foram contabilizadas vinte e três ameaças de juicio político advindas da oposição congressista e das elites econômicas contra o governo luguista (RODRÍGUEZ, 2012). Todavia, o êxito só seria obtido na vigésima quarta tentativa, após forte pressão midiática e da Igreja Católica, além das ações da Fiscalía (Ministério Público) e conivência do Poder Judiciário.

Los empresarios, los partidos tradicionales, el Parlamento, la administración de la Justicia, la prensa comercial, gran parte de la Iglesia católica, que no pueden darle un nombre digno a la sociedad oligárquica que defienden, que no pueden acusar con verdad a Lugo por lo que no hizo, combaten a un enemigo inexistente (el socialismo bolivariano del siglo XXI) y, con una mentalidad de Guerra Fría propia del siglo pasado, transformaron al Gobierno en enemigo. (CANESE, 2012, p. 56).

O estopim para a abertura do processo de destituição do mandatário foi o conflito agrário conhecido como Massacre de Curuguaty, que ocasionou a morte de 17 pessoas - 11 sem terras e seis policiais. Essas terras eram griladas pelo empresário e ex-presidente do Partido Colorado, Blas Nicolas Riquelme, que havia conseguido reintegração de posse junto à Fiscalía, apesar da existência de documentações alegando que as terras foram transferidas pela Marinha ao Instituto Nacional de Desarrollo Rural y de la Tierra (INDERT), com a finalidade de serem destinadas à reforma agrária.

A Fiscalía agiu parcialmente durante todo o processo da controversa reintegração de posse e no decorrer da investigação relacionada ao Massacre. Tal politização é apontada pelo documento apresentado pela Plataforma de Estudio e Investigación de Conflictos Campesinos (PEICC) (MARTÍNEZ, 2012). Toda a ação teve o intuito de criminalizar os camponeses e minar o governo que estava desgastado por não conseguir solucionar os conflitos agrários, adquirindo respaldo na comoção pública para, finalmente, lograr êxito em destituir Fernando Lugo da presidência. A tragédia na cidade de Curuguaty ofereceu a base fundamental para o início do processo golpista (MARTINEZ-ESCOBAR; SANCHEZ-GOMEZ, 2015, p. 291).

Don Blas usou todos os artifícios para adquirir de forma irregular o terreno fronteiriço, que poderia ser um retrato exemplar dos embates que giram há décadas em torno dos conflitos agrários. De toda a América Latina, o Paraguai é o país com maior concentração de terras nas mãos de poucos, enquanto uma imensa parcela da população segue vivendo miseravelmente.

Uma semana após o Massacre, no dia 22 de junho de 2012, o juicio político se concretizaria graças a aliança do Partido Liberal com seu inimigo, o Partido Colorado. O pacto atraiu os demais partidos de centro e direita. O processo foi relâmpago e sumário. Na noite anterior, foi aceito por ampla maioria dos deputados federais a acusação contra o presidente, designando cinco deputados oposicionistas para serem físcales e 
apresentarem o libelo acusatório, elaborado pela Câmara dos Deputados para julgamento, no dia posterior, no Senado Federal (LIBELO..., 2012).

O libelo continha argumentos genéricos e não afirmava quais eram os artigos ou as leis que o acusado havia infringido (LÓPEZ, 2014 apud MARTINEZ-ESCOBAR; SANCHEZ-GOMEZ, 2015, p. 287). Foram acusações puramente ideológicas sem apresentação de provas, pois, segundo o mesmo parecer, já eram de conhecimento público. Reproduzia-se as heranças da Ditadura Stronista, na qual não eram necessárias evidências para efetuar julgamentos políticos. Os meios de comunicação de massa operavam como sustentáculos da narrativa golpista, atribuindo uma legitimidade processual à destituição que era inexistente. O mesmo monopólio da comunicação que, desde o início, empenhava-se em desqualificar o governo progressista paraguaio.

A classe política buscou atribuir legalidade ao procedimento recorrendo a interpretações simplistas dos dispositivos constitucionais. Não importava, ainda, se o presidente teria poucas horas para elaborar e apresentar sua defesa perante o Senado. Não dependia das leis, da Constituição e nem dos princípios jurídicos, senão da quantidade de votos dos parlamentares (ESCOBAR, 2012, p. 90).

A conivência do Poder Judiciário foi crucial para efetivação do juicio político. O pedido ortogado pela defesa, na Suprema Corte, referente à inconstitucionalidade do processo por ausência de respeito ao direito de defesa, baseado no artigo 17 da Carta Magna, só foi respondido na semana seguinte ao julgamento e tendo o pedido negado por se tratar de um juízo político e não jurisdicional. No dia do julgamento, um documento descrevendo o procedimento que o Senado Federal adotaria no dia foi interceptado. O mesmo incluía como ocorreria a posse do vice-presidente, Frederico Franco. Após a descoberta, a defesa entrou novamente com um pedido de anulação do processo, junto à Corte, que veio a ser julgado e negado meses após o fato.

Lugo foi destituído por 39 votos favoráveis e quatro votos contrários. O seu vice-presidente, Frederico Franco, que rompera com o governo luguista, desde 2009, assume o cargo de chefe do Executivo ${ }^{2}$. Paraguai foi testemunha do auge do neogolpismo na América Latina (TOKATLIAN, 2012, p.1).

A UNASUL, MERCOSUL e alguns governos latino-americanos se posicionaram contrários ao processo de impeachment por considerarem que os tramites legais não foram respeitados. O Paraguai foi suspenso das decisões políticas dos dois órgãos, enquanto a Organização dos Estados Americanos (OEA) compreendeu que o processo foi legítimo e emitiu parecer favorável à permanência do país sem nenhuma advertência.

O novo governo instalado foi um fracasso e buscou desmontar decisões tomadas pelo governo luguista. Revogou a decisão que submetia o agronegócio a leis mais rígidas de atuação no território nacional, implantou medidas que retrocederam os avanços da reforma agrária, investiu bilhões na multinacional Rio Tinto Alcan, aumentando a dívida externa, reprimiu violentamente manifestações populares que se intensificaram após o impedimento, e teve o mandato marcado por escândalos de corrupção. A intensificação da crise política e representativa chegou ao nível de alguns senadores cogitarem, mais uma vez, o juicio político em poucos meses de mandato.

Frederico Franco teve o seu governo caracterizado por altos índices de impopularidade e permaneceu no poder até agosto de 2013, quando o colorado Horacio Cartes assume a Presidência da República, restaurando o domínio do partido no Poder Executivo. O balanço dos últimos quatro anos de seu governo é marcado por retrocessos nos direitos sociais, retorno da política neoliberal, forte repressão policial e censura ${ }^{3}$. Mas há, também, a reorganização das forças progressistas e movimentos populares em torno das eleições de 2018, apostando no retorno de Fernando Lugo, que é o pré-candidato com melhor índice de popularidade, para que seja reestabelecida a ordem democrática.

\section{Brasil}

A vitória eleitoral de Dilma Rousseff, em outubro de 2014, concedia ao Partido dos Trabalhadores (PT) seu quarto mandato consecutivo no Executivo nacional. Desde esse momento, o golpe de Estado começou a ser gestado. Após o resultado do segundo turno, a candidatura opositora do Partido da Social Democracia Brasileira (PSDB), não reconheceu o resultado. Alegando fraude, a oposição, naquele momento liderada por Aécio Neves, buscou evitar a aprovação do processo por meio da Justiça Eleitoral, chegando a solicitar auditoria das urnas eletrônicas. A tentativa não logrou. Agora, a esperança estava na possibilidade de impugnar a chapa PT-PMDB (Partido do Movimento Democrático Brasileiro) no Tribunal Superior Eleitoral (TSE). Fundamentavam-se na alegação de que a coalização havia recebido recursos ilegais. Expressando um sentimento antidemocrático de não aceitação do voto popular, a direita não concebia a ideia de esperar uma nova eleição e, dentro do jogo democrático, esforçar-se em conquistar o governo (PEREIRA, 2017).

O parlamento mais conservador desde a redemocratização elege Eduardo Cunha (PMDB) como presidente da Câmara Federal. Decididamente, o deputado fez forte oposição ao governo, ainda que seu partido, em tese, fosse da base. As propostas do Executivo não eram, propositalmente, colocadas em discussão, enquanto eram votadas as 
chamadas pautas-bomba, os projetos de lei que impactavam as contas públicas, prejudicando ainda mais o cumprimento das metas. Diversos parlamentares opositores votavam contra medidas que sempre defenderam, quando essas eram proposições do governo, comprovando que, de fato, desejavam boicotar e assistir "Dilma sangrar"4.

Logo no início do novo mandato, aprofundaram-se as investigações da Polícia Federal e juízes do estado do Paraná contra os políticos da base governista, conhecidas como Operação Lava-Jato. A operação mapeava uma rede de corrupção na principal empresa estatal e petrolífera, a Petrobrás, envolvendo, ainda, as principais empresas de construção civil do país. As sumárias prisões espetaculares e os chamados vazamentos seletivos, orquestrados entre os participantes do complexo jurídico-policial do Estado e a mídia hegemônica, criaram, como bem afirma Jessé Souza (2016, p. 110), "uma atmosfera de linchamento político". Estava preparada a criminalização de um partido, para que seu governo pudesse ser deslegitimado.

A grande imprensa conservadora agiu como uma espécie de partido político, seja propagando a narrativa de que o PT quebrou o Brasil, seja espetacularizando as denúncias de corrupção, manipulando fatos e criando um imaginário coletivo no qual o Partido dos Trabalhadores é uma organização criminosa empenhada em assaltar os bens públicos. A versão midiática não trabalhava por qualquer mudança real nas bases do sistema político que permite a compra da política pelo grande capital. Ao contrário, visava apenas à eliminação do inimigo político da vez, como sempre ocorreu na história dos golpes no Brasil (SOUZA, 2016).

\section{A atenção dada aos processos} políticos ocorridos em

Honduras, Paraguai e Brasil deixa evidente que os caminhos para 0

aprofundamento da qualidade democrática, no

subcontinente, não apenas se encerraram, mas estão em

processo de regressão (REIS, 2017).

Segundo Armando Boito Jr. (2012), o movimento operário e popular sempre foi o ponto de apoio à política de industrialização e capitalista. No período Varguista, a fração burguesa interessada em uma política industrial considerava uma ameaça o crescimento da atividade reivindicativa da classe operária e enxergava com desconfiança a condescendência do presidente Getúlio, levando-a a aderir à conspiração golpista, na crise de 1954. Como afirma Jessé Souza (2016, p. 43), "desde então, qualquer governo ou partido reformador tenta, sem sucesso, construir alianças com uma parte da classe dos proprietários", pois trata-se de "uma elite sem projeto para o país."

Armando Boito Jr. (2012) considera que, mais uma vez, a intervenção popular esteve de volta, em nossa história política, para que os governos Lula e Dilma pudessem superar a estagnação que predominou na década de 1990, pois foi através de um partido criado pelos setores populares, o PT, que a proposta de intervenção do Estado na promoção do bem-estar social e no desenvolvimento do capitalismo nacional foi retomada. $\mathrm{O}$ autor indica dois campos em que as elites estavam dividas no período que antecede a crise política: a frente neodesenvolvimentista, liderada pelo Partido dos Trabalhadores e representante de interesses heterogêneos de diversos setores da sociedade, e o campo neoliberal ortodoxo, liderado, sobretudo, pelo Partido da Social Democracia Brasileira (BOITO JÚNIOR, 2012, 2016).

Compunha a frente do novo desenvolvimentismo o empresariado nacional que atuava "na construção civil e naval, no agronegócio, na mineração, em variados ramos industriais e, inclusive, no setor financeiro" (BOITO JÚNIOR, 2016, p. 2). Já o campo da ortodoxia neoliberal, que fazia oposição ao governo, agregava os fundos financeiros internacionais, empresas industriais europeias e estadunidenses, casas de importação de veículos, alimentos, bebidas e outros produtos.

O governo do Partido dos Trabalhadores adotou uma política em que todos os setores sociais alcançavam ganhos significativos, especialmente os muito ricos e os muito pobres. No entanto, como afirma Jessé Souza (2016, p. 44-45), a elite que "manda no país pensa apenas no máximo de dinheiro no prazo mais curto possível", sendo incapaz de pensar "um projeto de longo prazo para o país". Demonstrando, então, sua vocação dependente (BOITO JÚNIOR, 2016), com o avanço da crise econômica, esses mesmos setores que outrora foram beneficiados com as políticas econômicas do período petista passam a atacar sistematicamente o governo. A Federação das Indústrias do Estado de São Paulo (FIESP), por exemplo, que por anos apoiou os governos do PT, passou a opor-se.

Como resposta à crise na economia, o governo reagiu adotando parte do programa derrotado nas eleições. Aplicou estratégias de cortes de gastos e diminuiu as verbas em programas sociais, o inverso do que havia prometido em campanha, configurando mais um caso de policy switch. Aos poucos, a base social tradicional do Partido dos Trabalhadores que garantira a vitória da candidata afastou-se do governo, abrindo caminho para uma 
ofensiva crescente da direita. Em paralelo, cresciam, desde o início de 2015, as manifestações conservadoras que, segundo dados do Datafolha, eram majoritariamente branca e de classe média. Tais protestos que exigiam impeachment já e abrigavam setores que pediam intervenção militar para barrar o bolivarianismo, foram amplamente divulgadas, para não dizer convocadas, pelos grandes monopólios de comunicação, em especial a Rede Globo. Associações empresariais, como a Federação das Indústrias de São Paulo, que apoiavam abertamente a destituição da presidenta, agiram como financiadores das mobilizações (PEREIRA, 2017).

De 2015 para 2016, partidos aliados decidiram romper com o governo, incluindo o partido do vicepresidente Michel Temer, o PMDB. Em dois de dezembro, o então presidente da Câmara dos Deputados, na oposição e em vias de ter seu mandato cassado por crimes de corrupção, abriu o processo de impeachment contra a presidenta. Com ele na liderança, partidos de direita e centro-direita ligados ao agronegócio, ao empresariado e a grupos religiosos fundamentalistas, realizaram o afastamento da mandatária Dilma Rousseff. A chefe do Executivo não estava sendo denunciada por crimes de corrupção, como os parlamentares que a destituíram, todavia por suposta irregularidade contábil, as chamadas pedaladas fiscais (prática recorrente em governos anteriores), que teriam sido utilizadas para cobrir déficits nas contas públicas, desrespeitando a Lei Orçamentária e a Lei de Responsabilidade Fiscal. Aceito na Câmara Federal e enviado ao Senado, o processo culminou no impedimento da presidenta, sendo substituída por seu vice.

O procedimento que duraria seis meses contou com a conivência do Supremo Tribunal Federal, que se absteve de declarar a inconstitucionalidade do golpe em curso. A justificativa era de que o rito do processo estava sendo rigorosamente cumprido e não julgariam o mérito, isto é, se houve ou não crime de responsabilidade. Sobre isso, Guilherme Simões Reis (2017, p. 4) afirma que um "guardião da Constituição que se prende ao rito e não avalia o mérito é tão efetivo quanto um cérbero, o cachorro de três cabeças guardião do Hades, desprovido de dentes".

O golpe pseudolegal (LÖWY, 2016), o neogolpismo, instalou um governo ilegítimo que se apresentava como a salvação nacional. O governo de Michel Temer aplica um programa neoliberal na economia e conservador no social, totalmente diferente do programa eleito em 2014. Isso se traduz na abertura da exploração do pré-sal para multinacionais petrolíferas; na aprovação de uma emenda constitucional que estabelece um teto de investimentos por duas décadas que, na prática, significará o sucateamento da saúde e educação pública; na proposta de reforma previdenciária que dificulta trabalhadores e mulheres mais pobres de aposentarem-se, aumentando o tempo mínimo de contribuição; na reforma trabalhista que possibilita a terceirização irrestrita e precariza condições de trabalho; na proposta Escola Sem Partido que censura e limita o exercício dos educadores e na aceleração de projetos que marginalizam a população LGBT, negra e feminina.

A ruptura democrática vivida, no Brasil, expressa o sentimento de uma elite econômica que, como pontua Michel Löwy (2016, p. 64), "não se contenta mais com concessões: ela quer o poder todo. Não quer mais negociar, mas sim governar diretamente, com seus homens de confiança, e anular as poucas conquistas sociais dos últimos anos". Foi inaugurado, com o impeachment sem crime, um novo momento para o país. Há aumento da perseguição e criminalização dos movimentos sociais, com perseguição aos seus militantes e dirigentes. Manifestações são fortemente reprimidas e participantes presos por terrorismo ou participação de organizações criminosas. Jornalistas contrários ao golpe são conduzidos coercitivamente para depor, sem ocorrência de intimação anterior. Verdadeiros massacres em comunidades camponesas e indígenas na região Centro-Oeste e Nordeste do Brasil contam com o silêncio cúmplice do governo. O novo governo flexibiliza a compra de armas de fogo e a base golpista, no parlamento, encaminha procedimentos para que o Estatuto do Desarmamento seja revogado. Estudantes são perseguidos por ocuparem escolas e universidades. O mais irônico é que o partido que a maioria do eleitorado rejeitou em 2014, o PSDB, hoje, está no Executivo, decidindo e formulando as políticas de um governo que ascendeu por meio de um golpe.

\section{Comparação}

Nos três casos, após o fechamento das urnas a oposição demonstra sua vocação antidemocrática ao não reconhecer o voto popular, seja através da revisão do resultado eleitoral ou em imediatos pedidos de destituição ainda na primeira semana de governo, como no caso Paraguaio. Tanto Dilma Rousseff, quanto Manuel Zelaya realizaram policy switch. No Brasil, mesmo após adotar a agenda da oposição de direita derrotada eleitoralmente, os partidos conservadores estavam dispostos a desestabilizar o governo, para tornar mais fácil sua destituição. No caso hondurenho, a oposição ganha força, sobretudo, quando o presidente eleito muda sua agenda, aproximando-se de propostas consideradas esquerdistas.

Após três mandatos consecutivos de políticas progressistas do Partido dos Trabalhadores, o mandato de Dilma Rousseff, em um cenário de crise econômica, era visto com desconfiança pelas elites econômicas, ainda que com mudança de agenda. Paraguai e Honduras, contudo, permaneciam com economias com relativo 
crescimento, à época, e, ainda assim, a oposição partidária e os setores empresariais mostraram-se intolerantes, desde o primeiro momento, a qualquer política orientada à justiça social.

Tanto Lugo, quanto Rousseff elegeram-se por coalizões com partidos conservadores. No primeiro caso, o vice-presidente de Lugo era do PLRA. No segundo, o vice-presidente era do PMDB. Ambos os segmentos mantinham forte ligação com as oligarquias locais, o agronegócio, o empresariado e, em dado momento da crise, abandonaram a base aliada, passando a ter forte atuação para concretização do impeachment. Com o êxito golpista, os dois partidos assumem o governo. Em Honduras, por tratar-se de um sistema bipartidário, o governo não teve a necessidade de compor com nenhum outro partido, tendo o PLH, partido de tradição à direita, alcançado maioria. Compartilhar da vivência partidária, todavia, não impediu que Zelaya fosse vítima de conspiração dentro próprio partido, a exemplo do líder da bancada liberal, na Assembleia Nacional, Roberto Micheletti, que efetuou forte oposição ao governo, fazendo-nos lembrar de Eduardo Cunha, líder da Câmara de Deputados, no Brasil, que era um governista, em tese, mas impedia o andamento das propostas do governo.

Nos três episódios neogolpistas, a participação, direta ou indireta, do sistema de justiça foi fundamental. No caso do brasileiro, ela ocorreu pela omissão do Supremo Tribunal Federal, quando se absteve de declarar a inconstitucionalidade da acusação, e pelo clima de linchamento político criado pelos vazamentos seletivos e espetacularização das investigações que afetavam políticos do governo. Em Paraguai, o Fiscalía atuou politicamente diante de um conflito de terra sanguinário que desgastou ainda mais o governo. Esse, por sua vez, passou a ser acusado de semear conflitos entre ricos e pobres. A Corte Suprema não atuou para defender o direito de defesa do presidente Fernando Lugo e fechou os olhos para um jogo em que o final já estava decidido previamente. Com Zelaya, a Corte atuou diretamente ao ordenar que as Forças Armadas o retirassem do palácio presidencial em armas e sem direito de defesa. Não faria sentido, portanto, classificar, qualquer dos três eventos, como golpe parlamentar. O judiciário não foi só omisso, foi agente!

A interferência da mídia monopolizada foi recorrente em Honduras, Paraguai e Brasil. Os principais meios de comunicação desses países dedicavam-se a desqualificar seus governos e respectivas políticas. Seja por meio de shows midiáticos feitos com denúncias de corrupção ou forjando um imaginário de uma suposta ameaça bolivariana. Nos três eventos, o oligopólio da mídia colaborou para a criação de um clima político em que a destituição não era apenas inevitável, mas necessária.

Analisamos o caso brasileiro como o mais sofisticado das três ocorrências neogolpistas aqui estudadas. A retirada de $\mathrm{Mel}$ do governo hondurenho contou com uma característica de tipo antigo bem demarcada: a intervenção direta dos militares que, após o destituírem, o exilaram em Costa Rica, acarretando em unânime condenação da comunidade internacional. Ainda que, posteriormente, a aparência institucional tenha sido preservada em Honduras, o distintivo militar difere-se dos acontecimentos paraguaio e brasileiro, nos quais as deposições ocorreram exclusivamente por dentro das instituições. Entretanto, ainda que os dois últimos processos tenham ocorrido de forma institucional, a não garantia do pleno direito de defesa de Fernando Lugo e a ligeireza do processo aumentam os questionamentos do juicio político. Mesmo que saibamos que o impedimento de Dilma Rousseff se deu sob cartas marcadas, ao cumprir-se o rito constitucional, maior feição legal foi conferida. Depreendemos, assim, que a discrição tem aumentado a cada novo ensaio golpista.

\section{Considerações finais}

O presente trabalho, através de uma análise preliminar, buscou indicar elementos para a investigação do papel da classe política, do poder judiciário, do oligopólio midiático e dos setores burgueses nos novos tipos de golpe na América Latina, o neogolpismo. A atenção dada aos processos políticos ocorridos em Honduras, Paraguai e Brasil deixa evidente que os caminhos para o aprofundamento da qualidade democrática, no subcontinente, não apenas se encerraram, mas estão em processo de regressão (REIS, 2017). Não afirmamos isso mirando no entendimento hegemônico, em que a alternância de poder é a virtude do sistema democrático. Para nós, a compreensão de democracia passa pelo critério da vontade popular tão desprezada pelos setores que, após terem sua hegemonia rompida ou seu projeto derrotado pela quarta vez consecutiva, rejeitaram o principal elemento da democracia liberal, o voto, para que um programa de preservação de privilégios e de retirada de direitos duramente conquistados pelas camadas mais pobres pudesse ser aplicado. Não podemos falar de consolidação democrática quando seus limites são tutelados pelos poderosos; quando esses dominantes, ao perderem esperanças de vitória nas urnas, decidem pôr fim a governos pós-neoliberais.

As eleições hondurenhas e paraguaias, que ocorreram em 2013, deram-se em um contexto de exclusão da oposição de espaços de atuação e aumento da repressão, contando ainda com denúncias de fraudes eleitorais, como denunciado por observadores internacionais, desde o país centro-americano (AGUILAR, 2013). O uso do sufrágio numa conjuntura pós-golpe não garante a redemocratização. Nada pode assegurar que as regras do jogo 
serão respeitadas, garantindo eleições livres e limpas. Ao contrário, as derrubadas de governos legítimos mostram exatamente a fragilidade dessas normas. Podem as eleições configurar uma "normalização da nova ordem" (MIGUEL, 2017) e, por parecer que a democracia foi restaurada, canalizar a luta popular produzida na resistência ao golpe para a sua própria legitimação. $\mathrm{O}$ voto é uma condição necessária para a democracia, porém não suficiente. As consequências dessas rupturas permanecerão. Derrotar o golpe significa desfazer essa herança. Dito isso, a luta extrainstitucional coloca-se, cada vez mais, como um instrumento necessário para a reconstrução e aprofundamento da democracia, não só em Honduras, Paraguai e Brasil, mas em toda a América Latina.

\section{Referências}

AGUILAR, A. Crise rima com América Central: o jogo que não termina em Honduras e a participação do Brasil. In: GORI, E. de (Ed.). Honduras 2013. Golpe de estado, elecciones y tensiones del orden político. Buenos Aires: Sans Soleil, 2013. p. 8-16.

BÄCHTOLD, F. Protesto cresce, mas manifestante mantém perfil de alta renda. Folha de São Paulo, São Paulo, 14 mar. 2016. Disponível em: <http://www1.folha.uol.com.br/poder/2016/03/1749640-protesto-cresce-mas-manifestante-mantem-perfil-de-altarenda.shtml>. Acesso em: 20 mar. 2017.

BIANCHI, A. O que é um golpe de Estado? Blog Junho, 26 mar. 2016. Disponível em: < http://blogjunho.com.br/o-que-e-um-golpe-deestado/>. Acesso em: 20 mar. 2017.

BOITO JÚNIOR, A. As bases politicas do neodesenvolvimentismo. Rio de Janeiro: Fundação Getúlio Vargas, 2012. Disponível em <http://bibliotecadigital.fgv.br/dspace/bitstream/handle/10438/16866/Painel\%203\%20-\%20Novo\%20Desenv\%20BR\%20\%20Boito\%20-\%20Bases\%20Pol\%20Neodesenv\%20-\%20PAPER.pdf?sequence=1>. Acesso em: 20 mar. 2017.

A natureza da crise política brasileira. Le monde diplomatique Brasil, São Paulo, 1 mar. 2016. Disponível em: <http:// diplomatique.org.br/a-natureza-da-crise-politica/>. Acesso em: 20 mar. 2017.

CANESE, R. Las causas de la destrucción del Estado de derecho. In: CARBONE, R; SOLER, L. (Ed.). Franquismo en Paraguay: el golpe. Buenos Aires: El 8vo. Loco, 2012. p. 78-84.

CUNHA FILHO, C. M.; COELHO, A. L.; PÉREZ FLORES, F. A right-to-left policy switch? An analysis of the Honduran case under Manuel Zelaya. International Political Science Review, v. 34, n. 5, p. 519-542, nov. 2013.

DAHL, R. Poliarquia: participação e oposição. São Paulo: Ed. da USP, 2005.

DOWNS, A. Teoria Econômica da Democracia. São Paulo: Ed. da USP, 1999.

ESCOBAR, T. Los golpes: Algunas consideraciones sobre la reciente ruptura del orden democrático. In: CARBONE, R.; SOLER, L. (Ed.). Franquismo en Paraguay: el golpe. Buenos Aires: El 8vo. Loco, 2012. cap. 10, p. 78-85.

FRANCO dice que está "listo para gobernar". Última Hora, Asunción, 16 jul. 2009. Disponível em: <http://www.ultimahora.com/ franco-dice-que-esta-listo-gobernar-n238112.html>. Acesso em: 10 abr. 2017.

GÓMEZ, R. La construcción de la democracia como relato nacional. A propósito del Golpe parlamentario. In: CARBONE, R; SOLER, L. (Ed.). Franquismo en Paraguay: el golpe. Buenos Aires: El 8vo. Loco, 2012. p. 57-63.

HARVEY, D. O neoliberalismo: história e implicações. São Paulo: Loyola, 2008.

LAHERA, E. Economía política de las políticas públicas. Economía UNAM, México, v. 1, n. 2, p. 34-51, 2004. Disponível em: <http:/ /www.scielo.org.mx/scielo.php?script=sci_arttext\&pid=S1665-952X2004000200004>. Acesso em: 20 mar. 2017.

LIBELO acusatório contra o presidente da República, Fernando Lugo Méndez. Resolução Honorável Câmara de Deputados n. 1431/ 2012. Mídia sem Máscara, 27 jun. 2012. Disponível em: <http://midiasemmascara.org/arquivos/unoamerica-expressa-seu-reconhecimentoao-novo-governo-paraguaio/>. Acesso em: 10 abr. 2017.

LLANOS, M.; MARSTEINTREDET, L. Ruptura y continuidad: la caída de "Mel” Zelaya en perspectiva comparada. América Latina Hoy, Salamanca, n. 55, p. 173-197, 2010. Disponível em: <http://revistas.usal.es/index.php/1130-2887/article/view/7267/7338>. Acesso em: 20 mar. 2017.

LÓPES SEGRERA, F. América Latina: crisis del posneoliberalismo y ascenso de la nueva derecha. Buenos Aires: CLACSO, 2016. LÖWY, M. Da tragédia à farsa: o golpe de 2016 no Brasil. In: JINKINGS, I.; DORIA, K.; CLETO, M. (Org.). Por que gritamos golpe? Para entender o impeachment e a crise política no Brasil. São Paulo: Boitempo, 2016. p. 61-68.

MANUEL Zelaya: 'Os EUA orquestraram o golpe de Estado em Honduras'. Diário Liberdade, 6 maio 2015. Disponível em: < https:/ /www.diarioliberdade.org/america-latina/direitos-nacionais-e-imperialismo/55743-manuel-zelaya-os-eua-orquestraram-o-golpe-de-estadoem-honduras>. Acesso em: 11 maio 2017.

MARTÍNEZ, A. Informe Masacre de Curuguaty. Asunción: Plataforma de Estudio e Investigación de Conflictos Campesinos, oct. 2012. Disponível em: <https://pt.scribd.com/doc/110616439/Informe-Curuguaty-PEICC>. Acesso em: 10 abr. 2017.

MARTÍNEZ-ESCOBAR, F.; SANCHÉZ-GÓMES, J. T. O golpe parlamentar no Paraguai: A dinâmica do sistema de partidos e o poder destituinte do Congresso. In: CRUZ, S. V.; KAYSEL, A.; CODAS, G. (Org.). Direita, volver! O retorno da direita e o ciclo político brasileiro. São Paulo: Perseu Abramo, 2015. cap. 14, p. 279-294.

MIGUEL, L. F. Lula não pode ser a normalização, O Blog do Demodê, 7 mar. 2017. Disponível em: <https:/grupo-demode.tumblr.com/ post/158104109662/lula-n\%C3\%A3o-pode-ser-a-normaliza\%C3\%A7\%C3\%A3o>. Acesso em: 20 mar. 2017. 
PALAU VILADESAU, T. El movimiento campesino en el Paraguay: conflictos, planteamientos y desafíos. OSAL: Observatorio Social de América Latina, Buenos Aires, v. 6, n. 16, p. 35-46, ene./abr. 2005. Disponível em: <http://biblioteca.clacso.edu.ar/clacso/osal/ 20110310112427/4Viladesau.pdf>. Acesso em: 11 abr. 2017.

PARAGUAY. Oxfam Internacional, 2017. Disponível em: <https://www.oxfam.org/es/paises/paraguay>. Acesso em: 11 maio 2017. PATEMAN, C. Participação e Teoria Democrática. São Paulo: Paz e Terra, 1992.

PERISSINOTO, R. Por que golpe? 2016. Disponível em: <https://www.academia.edu/29221192/Por_que_golpe >.Acesso em: 20 mar. 2017. PEREIRA, F. Democracias Errantes: reflexões sobre experiências participativas na América Latina. Rio de Janeiro: Ponteio, 2015.

. Fin de la marea rosa y neogolpismo en América Latina. 2017. Disponível em: <http://www.academia.edu/29936322/

Fin_de_la_marea_rosa_y_neogolpismo_-_Fabricio_Pereira>. Acesso em: 20 mar. 2017.

. Vitórias na Crise: trajetórias das esquerdas Latino-Americanas Contemporâneas. Rio de Janeiro: Ponteio, 2011.

ROMERO, R. Honduras: la difícil opción democrática. Buenos Aires: CLACSO, 2014.

REIS, G. S. O Fim da Era das Democracias na América. Breviário de Filosofia Pública, Rio de Janeiro, n. 146, p. 32-47, 23 abr. 2017. Disponível em: <http://estudoshumeanos.com/2017/04/23/o-fim-da-era-das-democracias-na-america/>. Acesso em: 20 mar. 2017.

RODRÍGUEZ, J. C. Los motivos del lobo. O el Golpe parlamentário. In: CARBONE, R; SOLER, L. (Ed.). Franquismo en Paraguay: el golpe. Buenos Aires: El 8vo. Loco, 2012. p. 49-56.

SADER, E. A nova toupeira: os caminhos da esquerda latino-americana. São Paulo: Boitempo, 2009.

. Refundar el Estado: posneoliberalismo en América Latina. Buenos Aires: CLACSO, 2008.

SCHUMPETER, J. Capitalismo, socialismo e democracia. Rio de Janeiro: Fundo de Cultura, 1961.

SOUZA, J. A radiografia do golpe: entenda como e por que você foi enganado. Rio de Janeiro: Casa da Palavra, 2016.

TAQUARI, F. "Não quero o impeachment, quero ver a Dilma sangrar”. Valor Econômico, São Paulo, 9 mar. 2015. Disponível em: <http:/ / http://www.valor.com.br/politica/3944096/nao-quero-o-impeachment-quero-ver-dilma-sangrar-diz-tucano>. Acesso em: 13 maio 2017. TAYLOR-ROBINSON, M. M. Honduras: Una mezcla de cambio y continuidad. Revista de Ciencia Política, Santiago (Chile), v. 29, n. 2, p.471-489, 2009.

TOKATLIAN, J. G. El auge del neogolpismo. La Nación, Buenos Aires, 24 jun. 2012. Disponível em: <http://www.lanacion.com.ar/ 1484794-el-auge-del-neogolpismo>. Acesso em: 20 mar. 2017.

. Neogolpismo. Página/12, Buenos Aires, 13 jul. 2009. Disponível em: $<$ http://www.pagina12.com.ar/diario/elmundo/subnotas/

128159-41146-2009-07-13.html>. Acesso em: 20 mar. 2017.

\section{Notas}

1 Famílias Zuccolillo, Rubin, Angel González, Chena, Grupo Vierci, Domínguez Dibb e Wasmosy.

2 O vice-presidente Franco declarou ao Jornal Última Hora, em 2009, que estaria “Más que preparado para gobernar el país.” (FRANCO..., 2009, grifos nossos).

3 No dia 1 de abril de 2017, parte do Congresso Nacional foi incendiado, após a aprovação da reforma constitucional que permitiria a reeleição. Um militante da juventude liberal acabou assassinado dentro da sede do partido.

4 O Senador Aloysio Nunes (PSDB-SP), ex-candidato à vice-presidência, em seção na casa legislativa afirmou: "Não quero que ela saia, quero sangrar a Dilma [...]." (TAQUARI, 2015).

5 Segundoo instituto de pesquisa Datafolha, 77\% dosmanifestantes pró-impeachment naAvenida Paulista, em março de 2016, declararam ser de cor branca. 26\% dos entrevistados possuíam renda entre cinco e dez salários mínimos e 37\% entre dez e cinquenta salários mínimos (BÄCHTOLD, 2016).

\section{Matheus Alexandre Araújo}

matheus.alexander17@outlook.com

Graduando em Ciências Sociais pela Universidade Federal do Ceará (UFC)

\section{Vanessa dos Santos Pereira}

vanessa.pereira@alu.ufc.br

Graduanda em Ciências Sociais pela Universidade Federal do Ceará (UFC)

\section{UFC}

Av. da Universidade, 2995 - Benfica

Fortaleza - Ceará - Brasil

CEP: 60.020-181 